\title{
Adorno e a MUTAÇÃO DO CONCEITO DE IDEOLOGIA*
}

\author{
Felipe Ribeiro**** \\ UFABC - São Bernardo do Campo - SP
}

\begin{abstract}
RESUMO
O artigo busca explicitar o diagnóstico elaborado por Adorno no período pós-guerra, segundo o qual o conceito tradicional de ideologia teria perdido seu objeto no mundo totalmente administrado. Se nos termos marxistas tradicionais a ideologia funcionava a um só tempo como falsa consciência e promessa não cumprida, enquanto que o desencadeamento das forças produtivas, por sua vez, era tomado como a mola material para a realização dos conteúdos normativos contidos na ideologia burguesa, então o diagnóstico de Adorno segundo o qual no capitalismo tardio as relações de produção assumem certa primazia diante das forças produtivas vem para abortar a vigência dessa noção tradicional de ideologia. No mundo administrado, a ideologia não estaria mais nas objetivações espirituais que operam como um véu sobre as relações materiais, mas, nos termos de Adorno, seria o próprio "rosto assustador do mundo", o que faz ideologia e realidade "correrem uma em direção à outra". Tudo se passa como se a atual consciência do capitalismo contemporâneo não mais legitimasse seus processos por meio de sua escamoteação ideológica, mas enunciasse seu próprio fundamento econômico com força apologética, fazendo da realidade sua própria ideologia. Neste texto, buscaremos reconstruir essa ideia com mais detalhe. Palavras-chave: Adorno. Crítica da ideologia. Mundo administrado. Capitalismo tardio. Teoria crítica.
\end{abstract}

* Trabalho apresentado na II Semana de Filosofia da Universidade Metodista de São Paulo. São Bernardo do Campo, SP, 14-17 out. 2019.

** Mestre em Filosofia pela Universidade Federal do ABC (UFABC).

E-mail: feliperibeiro1848@gmail.com. 
Que ideologia signifique falsa consciência, isso parece ser matéria de algum consenso. No entanto, discernir que essa falsidade contém mesmo assim alguma verdade, parece ser no mínimo contraintuitivo. Como dizer que a falsidade é ao mesmo tempo verdadeira? Embora correndo risco de mero jogo verbal, é justamente esse discernimento do momento de verdade decantado na falsa consciência que separa a concepção dialética de ideologia, presente em Adorno (assim como outros teóricos críticos), de outras concepções, seja a positivista, seja aquela persente na assim chamada sociologia do conhecimento (Mannheim). Podemos dizer que se trata de um conceito enfático de ideologia, a ponto de Adorno atribuir-lhe a capacidade de servir de sismógrafo histórico, como gostava de dizer da arte, de forma que a ideologia se tornará doravante categoria mestra para o diagnóstico da reversão brutal produzida pelo capitalismo na segunda metade do século XX. Este será o tema do texto a seguir.

Retomemos inicialmente a origem do dialético de ideologia. Como se sabe, sua matriz é a crítica da religião - "pressuposto de toda crítica" (MARX, 1981, p. 378) -, remetendo ao jovem Marx, em especial ao do texto de introdução àCrítica da filosofia do direito de Hegel. A religião, aqui, não é apenas falsa, isto é, não é apenas projeção de um mundo fictício no além (o que Feuerbach chamaria de momento teológico e por isso falso da religião), mas ela é ao mesmo tempo "oautossentimento e a autoconsciência do homem" (MARX, 1981, p. 378), de forma que nela é possível projetar o que a humanidade gostaria de ver realizada na terra (o que Feuerbach chama de momento antropológico e por isso verdadeiro da religião), sendo portanto uma forma de protesto contra a miséria atual: "A miséria religiosa é, por um lado, a expressão da miséria efetiva e, por outro, o protesto contra a miséria efetiva. A religião é o suspiro da criatura oprimida, o ânimo de um mundo sem coração, assim como o espírito de circunstâncias destituídas de espírito" (MARX, 1981, p. 378). Por isso, a religião é sempre o índice necessário de um estado real de sofrimento presente - nesse sentido ela é verdadeira, articulando conflitos sociais reais. 0 que lhe permite sobretudo funcionar como meio de conhecimento, pois quando se projeta em outro mundo um ideal de humanidade em paz, está ao mesmo tempo 
se dizendo que neste mundo não há tal condição, enunciado portanto uma verdade sobre ele. É nessa separação, na criação de dois mundos, um idílico e outro infernal, que reside a um só tempo a falsidade da religião e sua verdade, a mentira do anúncio de outra vida no além que nunca virá e ao mesmo tempo a denúncia correta da realidade atual.

Do ponto de vista prático, a tarefa se converte não apenas em desenganar a consciência aprisionada em ficções religiosas, mas "abandonar uma situação que necessita de ilusões” (MARX, 1981, p. 378), isto é, superar a miséria e realizar neste mundo a humanidade projetada na religião. Cabe à crítica dissolver a religião, negando sua falsa transcendência, mas ao mesmo tempo realizando seu conteúdo verdadeiro. Negar a ideologia significa tornar sua promessa efetiva na terra. Salvo engano, isso é uma das coisas que separa uma concepção marxista vulgar de ideologia de outra dialética, na medida em que a primeira considera a ideologia burguesa apenas o lixo (e aqui é um discurso coerentemente mais próximo d'A ideologia alemã) que deve ser eliminado do caminho para o bom progresso da luta socialista, enquanto outra entende que se deve realizar ideais burgueses que são corretos, sendo falsa sua promessa de já estarem em operação na sociedade burguesa. É por isso que, para Marx, a superação da religião - e para além dela, das ideologias em geral - é ao mesmo tempo sua realização. Como diz ele a respeito da filosofia, que havia tomado na atualidade recente a tarefa antes relegada à religião: "vocês nãopodem suprassumir a filosofia sem realizá-la" (MARX, 1981, p. 384). Assim, a luta socialista não se opõe aos ideais burgueses enquanto tais, mas à sua falsa realização no mundo dado, vendo-se portanto como uma luta para a realização efetiva desses ideias. É nesse sentido que, para Marx, o proletariado havia, em 1848, usado as "armas" que a burguesia "forjou" na luta contra o feudalismo contra ela mesma, que os deuses dela (liberdade, igualdade etc) "a abandonaram" (MARX, 1960, p. 153), migrando de campo na luta social, o que explica aliás a reversão ideológica que a classe burguesa, até então revolucionária, sofre depois de 1848, tornando-se abertamente reacionária, como mostrou Lukács (1968).

Ao mesmo tempo, Marx desenvolve uma tese sobre a matriz material que deveria disponibilizar as condições técnicas para a efeti- 
vação desse programa. Para irmos direto ao ponto, trata-se do teorema das crises entre forças produtivas e relações de produção, tal como exposto no prefácio à Para a crítica da economia política (cf. MARX, 1961, p. 7-11). Segundo o esquema, o metro de avaliação da atualidade histórica é sempre fornecido pelo índice de desenvolvimento das forças produtivas. Se assumirmos que as formações ideológicas espirituais fazem parte daquelas relações de produção que vão se tornando inadequadas aos novos quadros produtivos que são inaugurados pelo progresso técnico, então podemos entender que as crises entre esses ambos dois momentos não servem apenas para desfazer relações de produção ultrapassadas, mas ao mesmo tempo realizar o que elas tinham antecipado de justo. A crítica marxista da ideologia deveria portanto ser um fator de impulsão do revolucionamento das forças produtivas para a conquista das condições materiais necessárias para a efetivação dos ideais na terra. Se algum dia esse contexto fosse alcançado, a religião enquanto tal, assim como a filosofia e a arte, não seriam mais necessárias enquanto esferas separadas da vida. Note-se que aqui está o cerne da diferença com relação à crítica feuerbachiana da religião e da filosofia, pois embora Feuerbach tenha reduzido a religião ao seu criador, o homem sensível, ele tomou este no entanto de maneira abstrata, como homem sensível enquanto tal, sem entendê-lo como criado historicamente pelas relações sociais. Com isso, Feuerbach não conseguiu compreender que o próprio homem é um sujeito histórico e que portanto pode ser radicalmente modificado, o que é um forte componente da utopia marxista, como mostra Ruy Fausto (1999, p. 25). A crítica marxista da ideologia buscaria então equalizar ambos momentos: ao mesmo tempo negação da ideologia em nome de sua realização, mas também transformação da forma dada de homem em nome da realização de suas promessas. Não só a ideologia deve ser reduzida para coincidir com a realidade, mas nesse processo a realidade deve ser transformada para corresponder à ideologia. É uma via de mão dupla.

É fácil ver que é esta noção de ideologia que interessa não só a Adorno, mas podemos notar também, se dermos um passo atrás, que é ela que informa os textos da década de 1930 de Horkheimer. 
Basta nos reportarmos a um texto como "Materialismo e moral", em que Horkheimer deixa claro que a moral, cujos atributos são típicos da era burguesa, como liberdade, autodeterminação, oposição aos interesses materiais etc, "não é de modo algum descartada pelo materialismo como sendo mera ideologia, no sentido da falsa consciência" (HORKHEIMER, 2011, p. 65), pois o que é insustentável não são são "as ideias da burguesia, mas as condições que lhe não correspondem [...] Por isso, uma política correspondente não deve abandonar estas exigências, mas realizá-las" (HORKHEIMER, 2011, p. 78).Se passarmos para Adorno, veremos que, em vários textos e em espírito semelhante, Adorno não cansa de insistir: ideologia não é apenas falsa consciência, mas aparência socialmente necessária (ADORNO, 2003d, p. 558). Nela está em jogo a separação entre uma esfera espiritual e outra social, mas de forma que essa cisão ao mesmo tempo enuncia uma verdade sobre a sociedade atual. A esfera espiritual possui uma pretensão de verdade, mas que não pode corresponder à realidade dada sem contradizer a si mesma. De forma que a crítica da ideologia, diz ele (ADORNO, 2003d, p. 466), é negação determinada, em sentido hegeliano, na medida em que nega uma formação espiritual mas para com isso produzir uma nova situação histórica que tenha absorvido os conteúdos verdadeiros das expectativas passadas. Assim, a crítica da ideologia confronta a sociedade burguesa com suas próprias normas para verificar se ela corresponde ao seu próprio conceito, um acordo que então deveria ser o horizonte da lutra histórica. Digamos então que a crítica da ideologia é pensada num esquema de filosofia da história.

Se nos voltarmos aos textos de estética do Adorno, veremos com facilidade como essa noção de ideologia está presente na compreensão das promessas contidas na esfera artística. Na "Palestra sobre lírica e sociedade”, por exemplo, Adorno defenderá que o que há de ideológico na poesia lírica, a expressão exaltada de uma subjetividade não social, é ao mesmo tempo seu conteúdo social da lírica, na medida em que dessa maneira o poeta pode se contrapor à sociedade dada, buscando na expressão lírica a promessa de algo que escapa à experiência social, refugiado no mergulho lírico no próprio eu. Quase parafraseando a frase de Marx sobre a religião, Adorno diz que a lírica "implica o protesto 
contra uma situação social que cada indivíduo experimenta como hostil, alienada, fria e aflitiva, situação que ela estampa negativamente em sua própria configuração [...]. Em protesto contra ela [a sociedade], o poema enuncia o sonho de um mundo no qual tudo seria diferente" (ADORNO, 2003f, p. 52). Isso dá a chave para a interpretação de obras de arte, reaparecendo em diferentes momentos na obra de Adorno. Em Minima moralia, por exemplo, ele escreve que "O consolador das grandes obras de arte repousa menos no que elas pronunciam do que no que elas conseguem arrancar à existência" (ADORNO, 2003a, p. 255). Na Teoria estética, essa tese vem expressa da seguinte forma: "Pois a liberdade absoluta na arte, sempre apenas de um particular, vê-se em contradição com o estado perene de não liberdade no todo" (ADORNO, 2003c, p. 9). Em todo caso, temos aqui uma compreensão materialista da arte - e da ideologia em geral - que não serve para reduzi-la à sociedade em que tem origem, à posição de classe de seu autor etc, mas para dizer que, se a obra forbem sucedida em suas pretensões intrinsecamente estéticas, então ela ganha valor social justamente por produzir uma experiência que se contrapõe ao mundo alienado em que vivemos.

No entanto, é justamente esse conceito de ideologia (que Adorno chama de tradicional) que perderá sua vigência no capitalismo pós-guerra. Indo direto ao ponto, Adorno identificará simplesmente o desativamento daquele motor material mencionado acima. 0 capitalismo contemporâneo, ao desenvolver uma série de mecanismos de controle e administração racional, passou a intervir conscientemente no plano da economia para a estabilização de conflitos presentes na esfera econômica, de forma a atenuar as crises e garantir a sobrevida do capitalismo. Do ponto de vista do teorema marxista, isso produziu o que Marcuse chamou de simbiose entre forças produtivas e relações de produção, e que o próprio Adorno identificou como uma primazia das relações de produção sobre as forças produtivas: "A marca da época é a preponderância das relações de produção sobre as forças produtivas, que há muito tempo, porém, ridicularizam das relações" (GS8, p. 363), de forma que, "[m]ais do que nunca, as forças produtivas são mediadas pelas relações de produção; tão completamente, talvez, que estas aparecem, justamente por isso, como a essência; elas se torna- 
ram totalmente uma segunda natureza" (ADORNO, 2003d, p. 365). Isso não significa nada menos do que o fato de que o potencial explosivo das forças produtivas perde sua força, para ter seu desenvolvimento dirigido a favor das relações sociais dadas, e não para torná-las ultrapassadas. Ora, isso não é nada casual para Adorno, pois trata-se de um mecanismo desenvolvido pelo capitalismo para se perpetuar justamente no momento em que as condições técnicas necessárias para sua superação e assim para a produção de um estado social sem miséria já foram dadas. Em vários textos, Adorno sempre repete: hoje, com as forças produtivas disponíveis, ninguém mais na terra precisa passar fome, mesmo nos países periféricos. As relações capitalistas teriam se tornado, segundo o esquema marxista, supérfluas, completando sua função histórica. A sociedade administrada é justamente a forma de conservar tais relações no momento em que elas já se tornaram caducas. É por isso que Adorno escreve na Dialética negativa que "[d]iante da possibilidade concreta da utopia, a dialética é ontologia do estado falso" (ADORNO, 2003b, p. 22).

Ora, mas o que interessa a Adorno é sobretudo extrair as consequências ideológicas dessa mutação de pele do capitalismo. Com a passagem para a sociedade administrada, na medida em que as próprias classes dominantes tiveram que tomar consciência da dinâmica interna do capitalismo para geri-la em nome de sua perpetuação, a consciência geral acabou sendo a de um reconhecimento não ideológico da realidade social. 0 discernimento da não correspondência do capitalismo com suas próprias aspirações universais torna-se uma verdade ao alcance da mão justamente daquela classe dominante que historicamente era a portadora ideológica das promessas burguesas. Em uma palavra, todo mundo sabe muito bem o que o capitalismo vem a ser, que ele não tem nada a ver com liberdade ou igualdade, nem nenhuma outra variante de poesia vitoriana a respeito do curso burguês do mundo. Como Habermas dirá alguns anos depois: "a consciência burguesa se tornou cínica; como as ciências sociais - especialmente o positivismo jurídico, a economia neoclássica e a teoria política recente - mostram, ela foi inteiramente esvaziada de conteúdos normativos vinculantes" (HABERMAS, 1979, p. 96-7). 
Por outro lado, se vimos que o fato é também que o capitalismo já alcançou as condições materiais que tornassem supérfluas suas relações de produção, o que significa portanto que o prazo de validade da função histórica do capitalismo, como compreendida pelos marxistas, expirou, então cabe dizer que é a própria necessidade social da ideologia, enquanto promessa de transcendência, que foi posta em cheque. Vimos que a religião, e da mesma maneira a filosofia, a arte etc, projeta em outra realidade a realização da humanidade porque nesta realidade não há ainda condições materiais suficientes para a realização da utopia. Ora, vimos que para Adorno não se pode mais dizer o mesmo a respeito do capitalismo contemporâneo, já que as condições técnicas para a emancipação estariam finalmente dadas. Assim, é a necessidade mesma de buscar auxílio em outra esfera espiritual que é dissolvida. Em certo sentido, Adorno não deixa de ser um autor que vê uma relação inversamente proporcional entre avanço tecnológico e intensidade utópica. Com o melhoramento técnico da vida, elevando o padrão de vida das classes trabalhadoras, disponibilizando poderosas tecnologias para uso diário, além de intensos dispositivos de entretenimento, a necessidade da utopia atrofiou.

Esse é o quadro histórico que permite Adorno lavrar o atestado de óbito da ideologia tradicional. Não que a ideologia tenha morrido, porém, mas que ela se transformou: “Com a crise da sociedade burguesa, o próprio conceito tradicional de ideologia parece perder seu objeto [Gegenstand]", dando lugar à "administração planejada do que um dia foi ideologia" (ADORNO, 2003d, p. 474). Aqui, ideologia e realidade "movem-se uma em direção a outra": "A ideologia não é mais um véu [Hülle], mas tão somente o rosto ameaçador do mundo" (ADORNO, 2003d, p. 477). Quer dizer, a ideologia passou de idealista para realista. Ideologia não é mais enganar a respeito da realidade do mundo ao traduzi-la em especulações espirituais que tornassem admirável o mundo novo produzido pelas relações capitalistas, mas uma espécie de descrição realista vulgar da dinâmica da realidade usada para legitimar sua inevitabilidade. Daí que Adorno possa dizer que ideologia e realidade estejam correndo uma em direção a outra, ou melhor, que a realidade esteja se tornando sua própria ideologia. No 
plano histórico, note-se que esse argumento antecipa o TINA ("There is no alternative") de Margareth Tatcher, mas também os pacotes de "ajuste" do FHC, e mesmo hoje ressoa toda vez que algum ministro só assume como aceitável aquelas propostas justificadas pelos números. Em todo caso, a realidade atual é justificada a partir de uma descrição econômica, encabeçada por experts, que não mentem mais a respeito da dinâmica econômica, mas a enunciam com exaustão e precisão enjoativa para dizer: a realidade é isso aí, não tem outro jeito, falar em liberdade é bonito, mas não põe a economia para funcionar. Tudo se passa, se quisermos, como se a própria realidade tivesse funcionando como o pastiche de uma crítica materialista vulgar da ideologia ${ }^{1}$.

Essencial nesse processo é a indústria cultural, um fator fundamental para controlar as consciências e adequá-las à realidade justamente no momento em que há condições suficientes para superar a realidade dada. Num trecho muito forte de um texto chamado "Teses sobre necessidade", Adorno fala da barbárie caracterizada pela transferência da dominação para dentro dos indivíduos, mas que "não se refere à possibilidade da barbárie depois da revolulão, e sim ao impedimento da revolução através da sociedade total" (393). Esse diagnóstico é claro: diante da possibilidade material de realização da utopia, é preciso desenvolver formas de controle da consciência para que não se tome conhecimento dessa possibilidade, para continuar achando que o mundo ainda não está preparado para um estágio melhor ou que o que está dado é o melhor dos mundos possíveis. Por isso o desenvolvimento de poderosas formas de entretenimento ou satisfação de demandas culturais no interior da realidade dada, como se aquelas aspirações espirituais que antes serviam de antecipação de outra realidade pudessem ser apaziguadas em acordo com a realidade dada. 0 potencial transcendente da cultura estaria simplesmente minado.

1 Para análise muito sugestiva mostrando de que forma a ideologia neoliberal funciona como pastiche do materialismo vulgar, ver Arantes (2004). No mesmo espírito, Roberto Schwarz (2012) busca mostrar que um saldo desconcertante desse tipo de transformação é que, na atual conjuntura, os marxistas se tornam bons candidatos para governas a marcha normal das coisas no momento em que elas são justificadas segundo argumentos materialistas. 
Note-se que, para Adorno, o que há de ideológico na indústria cultural não é tanto o conteúdo transmitido, como se esta série, este livro, esta banda, transmitissem conteúdos ideológicos que estabelecem uma filiação entre o público e valores conservadores, imperialistas, capitalistas, a favor desse ou daquele partido etc. Com a indústria cultural o conceito de ideologia se torna mais abstrato, a ponto de a própria ideia de se distrair se torna ideológica, de apenas ligar a TV ou o rádio e relaxar, uma vez que tal gesto está intrinsecamente ligado à reprodução do trabalho. Pouco importa se o indivíduo ligue a TV para assistir novela das 8 ou um concerto da filarmônica de Berlim na TV Cultura - pois, em todo caso, a ideia mesma de que às 8 horas é horário para ligar a TV e relaxar, não importa qual programação se assista, está ligada à reprodução da realidade dada. Na verdade, que diferentes programações para todos os gostos estejam disponíveis é ainda um argumento a favor da possibilidade de que diferentes desejos culturais sejam satisfeitos no interior desta realidade, sem precisar transformá-la. Por outro lado, para Adorno (2003e, p. 518-32), a televisão não seria ideológica por mentir sobre a realidade ou colocar um véu espiritual em cima da verdade, mas justamente em função de seu realismo. Pela televisão, a própria realidade em que os indivíduos vivem lhes é apresentada como fato natural, como algo irrevogável. Hoje, podemos reconhecer isso se notarmos que tanto a programação da manhã dos jornais quanto as noturnas são as mais recheadas de catástrofes e desastres: ninguém tenta mais enganar dizendo que este mundo é harmonioso, mas justamente inundar o sujeito de um oceano de notícias péssimas cuja lição geral para o imaginário é dizer: este mundo não tem mais jeito.

Finalmente, a própria estrutura da obra de arte não sairia incólume com a projeção da indústria cultural. Vimos que o que devolvia um valor de verdade ao teor ideológico das obras de arte, em seu sentido tradicional, era que elas tinham uma lógica estética diferente da lógica social, podendo funcionar portanto como reduto de experiências que são incompatíveis com a realidade dada - liberdade, felicidade, harmonia, subjetividade etc -, contendo uma função utópica, de protesto. Já nos anos 40, Horkheimer e Adorno (2017, p. 129) foram 
categóricos: a indústria cultural desfaz a diferença entre lógica social e estética, seja do ponto de vista da produção de obras culturais, seja do ponto de vista de sua recepção, de forma que a cultura deixa de ser uma esfera de relativa autonomia na qual os indivíduos poderiam experienciar aquilo que o cotidiano reificado pela mercadoria lhes havia roubado. Como eles diziam: no cinema de massas, a experiência é de uma reversão curiosa: não é tanto o fato de que o filme prolonga pra dentro das salas a realidade social externa, mas sim a experiência de que a realidade do lado de fora é uma extensão do filme, de maneira que está anulada a diferença entre arte e vida cotidiana. Se pudermos retomar os termos do início da apresentação: a ideologia tradicional era a um só tempo falsa consciência e promessa verdadeira; ora, com o capitalismo administrado, seu momento falso foi de fato negado, mas junto com o que tinha também de verdadeiro nele, como se jogasse a água do banho junto com o bebê (aliás título do aforisma 22 de Minima moralia). Podemos falar portanto de uma falsa negação da ideologia, enquanto que a teoria crítica gostaria de ser uma negação dialética da ideologia, ultrapassando-a para realizar seus conteúdos.

\section{REFERÊNCIAS}

ARANTES, Paulo. 0 pensamento único e o marxista distraído. In: Zero à esquerda. São Paulo: Conrad, 2004.

ADORNO, Theodor W.Gesammelte Schriften in 20 Bänden - Band 4: Minima Moralia. Reflexionen aus dem beschädigten Leben. Frankfurt Am Main: Suhrkamp, 2003a.

. Gesammelte Schriften in 20 Bänden - Band 6: Negative Dialektik. Jargon der Eigentlichkeit. Frankfurt Am Main: Suhrkamp, 2003b.

.Gesammelte Schriften in 20 Bänden - Band 7: Ästetische Theorie. Frankfurt Am Main: Suhrkamp, 2003c.

.Gesammelte Schriften in 20 Bänden - Band 8: Soziologische Schriften I. Frankfurt Am Main: Suhrkamp, 2003d.

.Gesammelte Schriften in 20 Bänden - Band 10: Kulturkritik und Gesellschaft. Prismen. Ohne Leitbild. Eingriffe. Stichworte. Anhang. 2 Bände. Frankfurt Am Main: Suhrkamp, 2003e. 
.Gesammelte Schriften in 20 Bänden - Band 11: Noten zur Literatur. Frankfurt Am Main: Suhrkamp, 2003f.

FAUSTO, Ruy. Sobre a política de Marx. In: Dissenso, n. 2, 1999, p. 19-34.

GYORGY, Lukács. Marx e o problema da decadência ideológica. In: Marxismo e teoria da literatura. Rio de Janeiro: Civilização Brasileira, 1968.

HORKHEIMER, Max. Materialismo e moral. In: Teoria crítica I. São Paulo: Perspectiva, 2011.

\& ADORNO, Theodor. Dialektik der Aufklärung. Frankfurt am Main: S. Fischer Verlag GmbH, 2017.

MARX, Karl. Der achtzehnte Brumaire des Louis Bonaparte. In: Marx-Engels Werke. Band 8. Berlim: Dietz Verlag, 1960.

. Zur Kritik der Politischen Ökonomie. In: Marx-Engels Werke. Band 13. Berlim: Dietz Verlag, 1961.

Zur Kritik der Hegelschen Rechtsphilosophie. Einleitung. In: Marx-Engels Werke. Band 1. Berlim: Dietz Verlag, 1981.

SCHWARZ, Roberto. Saudação a Sérgio Ferro. In: Martinha versus Lucrécia. São Paulo: Cia das Letras, 2012. 